\title{
DIAFANIZAÇÃO DE ESFREGAÇOS DE FEZES
}

\section{RSPSP-113}

Ferreira, C. S. \& Carvalho, M. E. de Diafanização de esfriegaços de fezes. Rev. Saúde públ., S. Paulo, 6:19-23, 1972.

Resumo: Nas mesmas condições de turbidez (transmitancia $=50 \%)$, as médias das quantidades de fezes por unidade de área de esfnegaço sofrem acréscimos quando, ao invés de água, usamse diluentes de indices de refração mais elevados. Calculados como fatores, esses acréscimos foram, em média, 3,17 para a soluçäo de sacarose a $54 \%$ ( $n=1,438)$, 1,95 para a solução de glicerina a 50\% $(n=1,411)$ e 1,50 para a solução de sacarose a $30 \%(n=1,385)$. A absorciometria fatoelétrica mostrou-se adequada $\grave{a}$ avaliação do rendimento do proaesso de diafanização de esfregaços de fezes.

UnItermos: Esfregaços fecais*; Diafanização*; Indice de refração*; Absorciometria.

\section{INTRODU C A O}

A quantidade de material contida por unidade de área de uma preparação fecal é limitada pela turbidez máxima compatível com a identificação de elementos parasitários.

0 baixo índice de refração da água
Claúdio Santos FERREIRA *

Maria Esther de CARVALHO * (n $=1,333$ ) torna pouco transparentes os objetos microscópicos nela imersos (BAKer 1, 1950). Meios de índices de refração mais elevados aumentam o rendimento do microscópio, sendo preferiveis. Os meios de montagem podem ser divididos em dois grandes grupos: misciveis e não miscíveis em água (Romers 6, 1948).

A diafanização de esfregaços de fezes por meio de óleo de cedro $(n=1,505)$ foi proposta por Heiv 4 (1927). Embora ofereça bom rendimento, há necessidade de prévia dessecação das preparações, - que torna inidentificáveis os ovos de várias espécies de helmintos, impossibitando também a pesquisa de cistos de protozoários.

A glicerina, um dos meios de monta gem de uso mais frequiente dentre os miscíveis em água, é empregada em solução aquosa a 50\%, na técnica de Kato e Miura para a preparação de esfregaços espessos de fezes (Komrya \& KuBAYASHI 5,1966$)$.

Considerando a analogia entre os métodos gerais de diafanização usados em microscopia ótica, efetuamos determinações turbidimétricas de suspensões de

Do Departamento de Parasitologia do Instituto de Ciencias Biomédicas da Universidade de Såo Paulo. - Av. Dr. Arnaldo, 455 - São Paulo, S.P. - Brasil. 
FERREIRA, C. S. \& CARVAlHo, M. E. de - Diafanização de esfregaços de fezes. Rev. Saúde públ., S. Paulo, 6: 19-23, 1972.

fezes em água ( $n=1,333$ ), solução de sacarose a $30 \%(n=1,385)$, solução de glicerina a $50 \%(n=1,411)$ e solução de sacarose a $54 \%(n=1,438)$. A turbidimetria fotoelétrica, empregada no presente estudo, possibilita a avaliação objetiva do rendimento do processo.

$O$ estado de conservação e as condições de visibilidade dos ovos de helmin. tos presentes em diversas das amostras de fezes examinadas foram objeto de verificação.

\section{MATERIAIS E MÉTODOS}

\section{Materiais:}

a) Câmaras para fotometria (Fig. 1) feitas a partir de lâminas de microscopia, para conter preparações de $1 \mathrm{~mm}$ de espessura; c) solução de glicerina a $50 \% \mathrm{v} / \mathrm{v} \mathrm{em}$ água $(\mathrm{n}=1,411)$;

d) solução de sacarose a $30 \% \mathrm{p} / \mathrm{v}$ em água $(\mathrm{n}=1,385)$;

e) solução de sacarose a $54 \% \mathrm{p} / \mathrm{v}$ em água $(\mathrm{n}=1,438)$.

Os índices de refração foram determinados com refratômetro de Abbe.

\section{Métodos:}

Amostras de fezes humanas normais (sólidas), em número de 20 , foram diluídas em água e nas soluções mencionadas. Os resíduos sólidos macroscópi$\cos$, excluídos por meio de catação.

De cada amostra de fezes foram separadas 4 porções de mesmo pêso e diluí

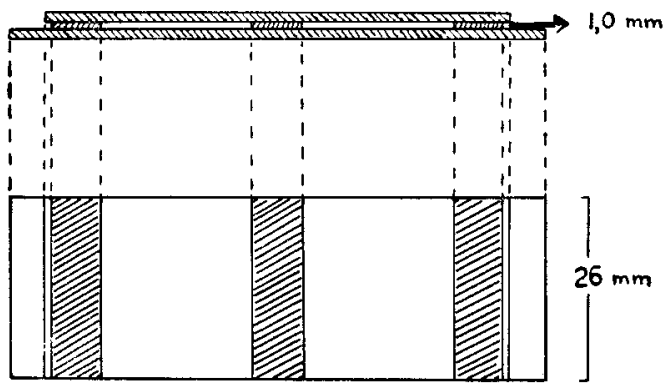

Fig. 1 - Câmara para fotometria.

b) absorciômetro bàsicamente seme lhante ao proposto por BEAVER ${ }^{2}$ (1949), dotado de célula fotorresistiva de CdS (LDR Phillips) e escala de transmitância. O diêmetro do feixe luminoso incidente sôbre a célula (após passagem pela câmara) foi reduzido para $5 \mathrm{~mm}$. Usaram-se diafragmas para evitar a entrada de luz difusa. A aferição foi feita por meio de filtros de transmitância conhecida, determinada com fotômetro graduado em "footcandles" (Frereira \& $C_{A R}$ VALHO ${ }^{3}$, 1971); das a 1:10, 1:20, 1:40, 1:80 e 1:160 em água e nas três soluções referidas.

Após homogeneização, transferiram-se, sucessivamente, tôdas as suspensões para as câmaras, determinando-se as respectivas transmitâncias em relação à água destilada. Consideraram-se valores médios de leituras correspondentes a diversas regiōes das preparações. Para cada diluição fecal, calculou-se a quantidade de material contida em uma área de $768 \mathrm{~mm}^{2}(24 \times 32 \mathrm{~mm})$ de uma câma- 
FERREIRA, C. S. \& CARVALHo, M. F. de - Diafanização de esfregaços de fezes. Rev. Saúde públ., S. Paulo, 6: 19-23, 1972.

ra de $1 \mathrm{~mm}$ de altura. Nas condiçóes mencionadas, as suspensões a 1:10, 1:20, $1: 40,1: 80$ e 1:160 contém, respectivamente, $80,40,20,10$ e $5 \mathrm{mg}$ de fezes.

Tendo BEAvER 2 (1949) sugerido o valor de $50 \%$ de transmitância para a padronização de esfregaços de fezes diluídos em água, calcularam-se, por meio de interpolação linear, as quantidades de fezes (de cada amostra e em cada diluente) contidas em esfregaços de $24 \times 32 \mathrm{~mm}$ e transmitância de $\mathbf{5 0} \%$. $\odot$ acréscimo da quantidade de fezes permitido pelas soluçōes diafanizadoras, em esfregaços com $50 \%$ de transmitância, expresso como fator, indica a eficiência do processo.

Ovos de Ascaris lumbricoides, Trichuris trichiura, Hymenolepis nana, Schistosoma mansoni e ancilostomídeos, presentes em várias das amostras, foram examinados em preparações delgadas, entre lâmina e lamínula, sob aumento de $\mathbf{4 0 0}$ diâmetros, para a verificação de eventuais alterações morfológicas. Não foram pesquisados protozoários.

\section{RESULTADOS}

Para cada amostra, no mesmo diluente e nas mesmas condições de transmitância, a quantidade de fezes por área unitária variou dentro de amplos limites.

Dentro de uma mesma amostra, em todos os casos, as menores quantidades de fezes por preparação com 50\% de transmitância $(31,2 \mathrm{mg}$ em média), correspondem ao material diluído em água. As suspensões em soluções de sacarose a $\mathbf{3 0} \%$, glicerina a $\mathbf{5 0} \%$ e sacarose a $\mathbf{5 4} \%$ apresentam, como valores médios, respectivamente $46,5,60,4$ e $98,8 \mathrm{mg}$.

Os acréscimos calculados como fatores são, em média, respectivamente 1,50 , 1,95 e 3,17 para as três soluções.

Uma permanência durante 48 horas, do material em qualquer das três soluções, não resultou em alterações morfologicas que dificultassem a identificação dos ovos de helmintos encontrados.

Os dados quantitativos da experiência constam da Tabela e da Figura 2.

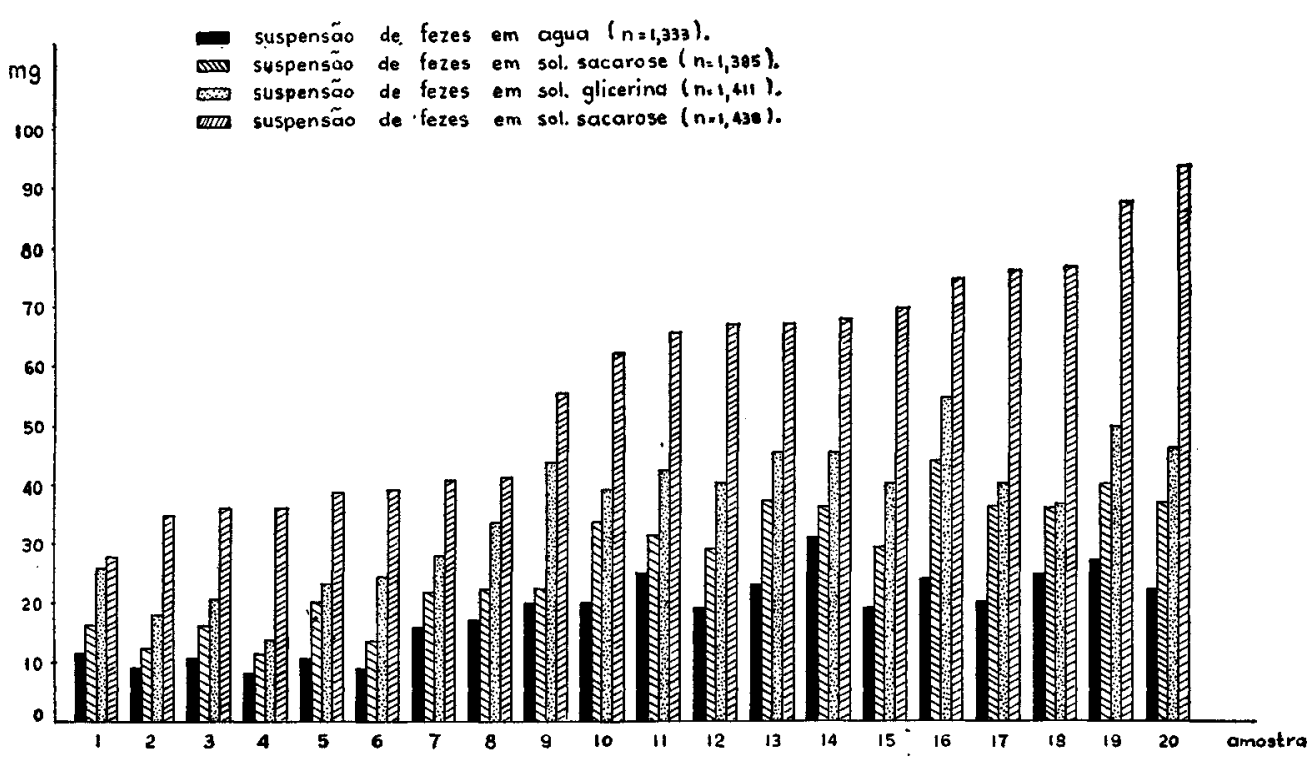

Fig. 2 - Quantidade de fezes contida em preparaçōes de 24 × 32mm e transparência $=$ $($ transmitancia $=50 \%)$. 
FERREIRA, C. S. \& CARVALHo, M. E. de - Diafanizaçăo de estregaços de lezes. Rev. Saúde públ., S. Paulo, 6: 19-23, 1972.

\section{I S C U S S A O}

Embora a quantidade de fezes contida em esfregaços diluídos em água, padronizados quanto às dimensóes e à turbidez, possa variar dentro de amplos limites, evidencia-se a utilidade da diafanização como um meio de aumentar o rendimento do exame de esfregaços diretos de fezes. Nos casos em estudo, êsse rendimento mostrou-se tanto maior quanto mais elevado $o$ índice de refração do meio. No caso da solução de sa carose a $54 \%$, entretanto, foi considerà. velmente superior ao do de índice de refração imediatamente inferior.

T A B E L A

Quantidade de fezes em $\mathrm{mg}$ a 50\% de transmitancia em preparaçōes de $24 \times 32 \mathrm{~mm}$.

\begin{tabular}{|c|c|c|c|c|c|c|c|}
\hline \multirow[t]{2}{*}{ Amostra } & \multirow{2}{*}{$\begin{array}{c}\begin{array}{c}\text { Fezes em } \\
\text { 6gua } \\
n=1,333\end{array} \\
\text { mg }\end{array}$} & \multicolumn{2}{|c|}{$\begin{array}{c}\text { Fezes em } \\
\text { Sol. sacarose } \\
\mathbf{n}=1,385\end{array}$} & \multicolumn{2}{|c|}{$\begin{array}{c}\text { Fezes em } \\
\text { Sol. glicerina } \\
\mathbf{n}=1,411\end{array}$} & \multicolumn{2}{|c|}{$\begin{array}{c}\text { Fezes em } \\
\text { Sol. sacarose } \\
\text { n }=1,438\end{array}$} \\
\hline & & $\mathbf{m g}$ & fator * & $\mathrm{mg}$ & fator * & mg & fator * \\
\hline 01 & 19,7 & 27,8 & 1,42 & 44,0 & 2,24 & 47,0 & 2,38 \\
\hline 02 & 15,4 & 21,2 & 1,38 & 30,8 & 2,00 & 59,2 & 3,78 \\
\hline 08 & 18,1 & 27,7 & 1,52 & 35,2 & 1,95 & 61,2 & 3,377 \\
\hline 04 & 13,8 & 19,7 & 1,41 & 23,3 & 1,68 & 61,3 & 4,42 \\
\hline 05 & 17,8 & 34,2 & 1,93 & 39,7 & 2,23 & 65,7 & 3,69 \\
\hline 06 & 15,2 & 22,9 & 1,52 & 41,5 & 2,13 & 66,6 & 2,74 \\
\hline 07 & 26,7 & 37,0 & 1,37 & 47,5 & 1,77 & 69,2 & 2,60 \\
\hline 08 & 28,9 & 38,3 & 1,33 & 57,2 & 1,92 & 70,2 & 2,41 \\
\hline 09 & 34,2 & 38,5 & 1,13 & 74,5 & 2,18 & 94,5 & 2,76 \\
\hline 10 & 34,2 & 57,2 & 1,68 & 66,7 & 1,95 & 106,0 & 3,10 \\
\hline 11 & 42,7 & 53,3 & 1,25 & 71,8 & 1,68 & 111,5 & 2,60 \\
\hline 12 & 32,2 & 49,6 & 1,54 & 68,3 & 2,16 & 113,5 & 3,55 \\
\hline 13 & 39,2 & 63,2 & 1,62 & 77,0 & 1,97 & 1113,5 & 2,92 \\
\hline 14 & 53,0 & 61,2 & 1,25 & 77,0 & 1,45 & 115,0 & 2,17 \\
\hline 15 & 32,5 & 50,0 & 1,54 & 68,3 & 2,11 & 118,0 & 3,63 \\
\hline 16 & 40,8 & 74,5 & 1,84 & 92,8 & 2,28 & 126,5 & 3,12 \\
\hline 17 & 34,2 & $61 ; 2$ & 1,79 & 67,8 & 1,98 & 129,2 & 3,78 \\
\hline 18 & 42,3 & 61,2 & 1,45 & 62,2 & 1,47 & $\pm 30,0$ & 3,12 \\
\hline 19 & 46,2 & 67,8 & 1,41 & 84,6 & 1,85 & 148,5 & 3,01 \\
\hline 20 & 37,6 & 63,0 & 1,67 & 78,2 & 2,08 & 159,0 & 4,25 \\
\hline
\end{tabular}

* Quantidade de fezes em água $x$ fator $=$ quantidade de fezes na solução indicada.

\section{ONCLUS OES}

As determinações de valores de turbidez fecais em termos de percentagens de transmitância mostraram-se adequadas à avaliação, de modo objetivo, do rendimento de processos de diafanização de esfregaços de fezes.

A análise dos resultados obtidos com substâncias de vários indices de refração dará flexibilidade ao critério de escolha dos meios, conciliando-se propriedades óticas com as de preservação dos caracteres morfológicos dos parasitas. A pesquisa de protozoários em material diafanizado poderá decorrer de estudos nesse campo. 
FGRreira, C. S. \& CARVALHo, M. I. de - Diafanização de esfregaços de fezes. Rev. Saúde públ., S. Paulo, 6: 19-28, 1972.

RSPSP-113

Ferreira, C. S. \& Carvalho, M. E. de [Clearing of fecal smears]. Rev. Saúde públ., S. Paulo, 6:19-23, 1972.

SUMmary: Under the same conditions of turbidity (transmittance $=50 \%$ ) the average amounts of feces per unit smear area are increased when diluents with high refractive indices are substituted for water. Such increments, calculated as factors, were on the average: 3.17 for $54 \%$ sucrose $(n=1.438) ; 1.95$ for $50 \%$ glycerol $(n=1.411)$; and 1.50 for $30 \%$ sucrose $(n=1.385)$ aqueous solutions. Photoelectric absorptiometry was found adequate for evaluating the efficiency of fecal smear clearing processes.

UNITERms: Fecal smears*; Clearing*; Refractive index*; Absorptiometry.

\section{REFERENCIAS BIBLIOGRAFICAS}

1. BAKER, J. R. - Cytological technique. 3rd ed. London, Methuen, 1950. Cap. 8.

2. BEAVER, P. C. - Quantitative hookworm diagnosis by direct smear. J. Parasit, 35 :125-35, 1949.

3. F'rrreira, C. S. \& CaRvalho, M. E. do - Simplificação do método de Beaver para a padronização de esfregaços de fe. zes. Nota prévia. Rev. paut. Med., $78: 35,1971$.

4. HEIN, G. - Cedar oil as an aid in finding parasitic ova in reces. $J$. Lab. clin. Med., 12:1117-8, 1927.

5. KOMIYA, Y. \& KOBAYASHI, A - Evaluation of Kato's thick-smear technic with a cellophane cover for helminth eggs in feces. Jap. J. med. Sci. Biol., 19:59-64, 1966.

6. ROMEIS, B. - Mikroskopische Technik, 15. aufl. Muenchen, Leibniz Verlag, 1948.

Recebido para publicagão em 25-10-1971

Aprovado para publicasáo em 7-1-1972 